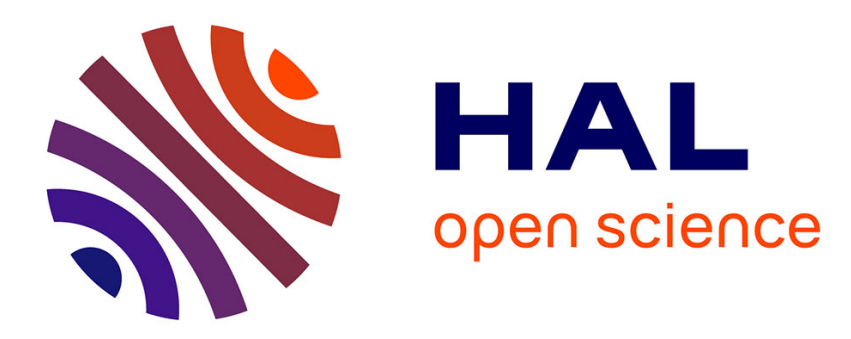

\title{
Optimal Diversity: Increasing Returns versus Recombinant Innovation
}

\author{
Jeroen C.J.M. van den Bergh
}

\section{To cite this version:}

Jeroen C.J.M. van den Bergh. Optimal Diversity: Increasing Returns versus Recombinant Innovation. Journal of Economic Behavior and Organization, 2008, 68 (3-4), pp.565. 10.1016/j.jebo.2008.09.003 . hal-00643025

\section{HAL Id: hal-00643025 \\ https://hal.science/hal-00643025}

Submitted on 21 Nov 2011

HAL is a multi-disciplinary open access archive for the deposit and dissemination of scientific research documents, whether they are published or not. The documents may come from teaching and research institutions in France or abroad, or from public or private research centers.
L'archive ouverte pluridisciplinaire HAL, est destinée au dépôt et à la diffusion de documents scientifiques de niveau recherche, publiés ou non, émanant des établissements d'enseignement et de recherche français ou étrangers, des laboratoires publics ou privés. 


\section{Accepted Manuscript}

Title: Optimal Diversity: Increasing Returns versus

Recombinant Innovation

Author: Jeroen C.J.M. van den Bergh

PII: $\quad$ S0167-2681(08)00183-2

DOI: $\quad$ doi:10.1016/j.jebo.2008.09.003

Reference: $\quad$ JEBO 2257

To appear in: Journal of Economic Behavior \& Organization

Received date: $\quad$ 6-7-2007

Revised date: $\quad 14-9-2008$

Accepted date: $\quad 14-9-2008$

Please cite this article as: van den Bergh, J.C.J.M., Optimal Diversity: Increasing Returns versus Recombinant Innovation, Journal of Economic Behavior and Organization (2008), doi:10.1016/j.jebo.2008.09.003

This is a PDF file of an unedited manuscript that has been accepted for publication. As a service to our customers we are providing this early version of the manuscript. The manuscript will undergo copyediting, typesetting, and review of the resulting proof before it is published in its final form. Please note that during the production process errors may be discovered which could affect the content, and all legal disclaimers that apply to the journal pertain. 


\title{
Optimal Diversity: \\ Increasing Returns versus Recombinant Innovation
}

\author{
Jeroen C.J.M. van den Bergh \\ ICREA, Barcelona, Spain \\ $\&$ \\ Institute for Environmental Science and Technology \\ \& Department of Economics and Economic History \\ Autonomous University of Barcelona \\ Spain \\ $\&$ \\ Faculty of Economics and Business Administration \\ \& Institute for Environmental Studies \\ Free University, Amsterdam \\ The Netherlands
}

Address:

Institute of Environmental Science and Technology (ICTA)

Autonomous University of Barcelona

Edifici Cn - Campus UAB

08193 Bellaterra (Cerdanyola)

Spain

Email : jeroen.bergh@uab.es and jbergh@feweb.vu.nl

Phone : 0034-93581.3747 (secr. 3324 or 3748)

Fax : 0034-93581.3331 


\title{
Optimal Diversity:
}

\section{Increasing Returns versus Recombinant Innovation}

\begin{abstract}
Choices regarding diversity play an important role in economics and innovation management, but often remain implicit. Once made explicit, the objectives of efficiency and diversity are usually posed as in conflict, as efficiency relates positively and diversity negatively to various increasing returns to scale in markets. Such a perspective, however, neglects the benefits of diversity in terms of realizing system improvements through recombinant innovation or spillovers. The latter implies a contribution of diversity to long-term efficiency. Dominant economic approaches that address diversity, such as option value and real options theories, regard benefits of diversity as exogenous. This paper proposes a simple model of variable, endogenous diversity to analyze the optimal balance between increasing returns to scale and recombinant innovation. It is discussed under which conditions one of four solutions is optimal: complete specialization regardless of which option, complete specialization in one specific option, symmetric diversity (perfect balance), and asymmetric diversity. The results give rise to a number of policy insights.
\end{abstract}

Key words: balance, disparity, distribution, economies of scale, efficiency, evolution, exploration vs. exploitation, investment theory, learning, R\&D.

JEL classification: B52, O31, Q28, Q42.

Acknowledgements: I am grateful to Andrew Stirling, Paolo Zeppini and three anonymous referees for helpful discussions and comments. 


\section{Introduction}

Choices regarding diversity play an important role in economics and innovation management, but they usually remain implicit or are simply neglected. If diversity is made explicit, it is often posed as conflicting with the goal of efficiency, based on the belief that efficiency relates positively and diversity negatively to various increasing returns to scale that are present at demand and supply sides of markets. For instance, in deciding about the investment of scarce funds, individuals, firms or public agencies are often in doubt whether to reap the benefits of scale economies by focusing investments on a single option, or whether to keep different options open at the cost of losing returns to scale. Investing in a diversity of options is then often quickly judged as wasting scarce means, on the basis of the argument that one was incapable of making a best choice. The objectives of efficiency (or cost-effectiveness) and diversity are then considered in conflict. It will be argued here that such a conceptualization is incomplete and can in fact give rise to non-optimal choices.

The above-sketched supposed opposition between efficiency and diversity represents a rather static perspective on scale-diversity trade-offs and neglects the benefits of diversity in terms of not just keeping options open but especially realizing system improvements. Such improvements may result from what can be called 'recombinant innovation' and 'spillovers between different options'. As these phenomena are positively related to diversity, they imply a contribution of the latter to future benefits and thus long-term efficiency. In evolutionary language this might be summarized as 'evolutionary progress'. In effect, this perspective means that an optimal investment decision really comes down to identifying the optimal level of diversity rather than choosing a particular option. Thus the fundamental question here is about the optimal degree of diversity, in terms of the number of alternatives invested in as well as the balance of investments in the various alternatives, ranging from uniform to very uneven.

To answer this question, a simple model of endogenous diversity, probabilistic recombinant innovation, and returns to scale is developed that can address the issue of dynamic welfare or cost-benefit analysis in a framework of changing diversity. This model will incorporate the following aspects of diversity. Diversity has a cost due to lost opportunities for enjoying increasing returns to scale. In addition, diversity is associated with benefits of innovation and progress as options are not static but dynamic and emergent through probabilistic recombination (or modular evolution) and spill-overs. A trade-off between these costs and benefits allows the assessment of optimal diversity. In line with Stirling (2007), three components of diversity will be assumed to have an impact on the probability of successful recombinant innovation, namely variety, balance and disparity. These notions are explained in Section 2. 
The approach adopted here is motivated by several related, unresolved problems. The mentioned trade-off between enjoying economies of scale and enjoying 'economies of diversity' really is a central issue in innovation theory and evolutionary economics, but it is somehow not recognized as such, which may explain why general theoretical insights and decision rules are lacking. On the other hand, in practice decisions on investment and innovation are regularly motivated by short-term efficiency, as is reflected by a common focus on cost-effectiveness and a widespread interest in short pay-back times of investments. Of course, such myopia is partly due to short-term interests being often better represented in reality than long term interests, with regard to both public and private investments. Another reason for myopia is that scale advantages are generally more clear and certain than diversity advantages, as the latter involve uncertain (probabilistic) recombinant innovations and spillovers. The short-term bias in the practice of investment decision making is possibly reinforced by the fact that existing investment theories, models and evaluation techniques are lacking attention to long-term efficiency that takes account of the dynamic character, impact and resulting value of diversity. This does not deny that diversity is recognized as important in innovation studies, but here it is mainly addressed through the descriptive notion of niche markets (e.g., Frenken et al. 1999, Tisdell and Seidl 2004, Schot and Geels 2007). A clear perspective on the precise trade-offs at stake when deciding about diversity is missing.

A particular motivation for the present study is the current, worldwide plea to make a rapid transition from the current fossil fuel dominated economy to production and consumption modes depending more on renewable energy, notably biofuels, wind and solar energy. The latter evidently require many investments in uncertain technological paths. Not surprisingly, this scares away many firms, politicians and voters, and instead many of these argue in favor of reaping short-term benefits by investing predominantly in energy conservation, capture and storage of $\mathrm{CO}_{2}$, and combined-heat-and-power. The latter options, however, run the risk of leading to a reinforcement of the fossil fuel economy, thus making an escape or 'un-locking' of it increasingly difficult (Geels 2002, van den Bergh et al. 2006). It seems that investors and politicians are hesitant to exchange fairly certain short-term costsavings for diversity with uncertain (but nevertheless likely) long-term economic and environmental benefits. As a result, it is pretty sure that choices currently made in this area are not optimal from a long-term social welfare angle (van den Bergh et al. 2006, van den Bergh 2007).

The problem of scale versus diversity addressed here is somewhat related to two other problems. The first is the so-called 'exploration versus exploitation dilemma' (March 1991). This is about the balance between research for new technologies and the development of existing knowledge. The second problem is known as "narrow windows, blind giants and angry orphans'. This is about managers or policy makers who make strategic choices and face 
the dilemma that it becomes ever more difficult to alter a current development path as the information on what is the optimal strategy increases (David 1986 and 1987). The analysis of these problems, however, does not specifically address recombinant innovation or spill-over and therefore differs fundamentally from the approach adopted here.

In addition, it is useful to position the proposed new approach in the field of investment theories. Dominant theories here are option value (Arrow and Fisher 1974, Henry 1974) and real options theories (Dixit and Pindyck 1994). These are different from the current approach in that they do not capture the intricate advantages and endogenous dynamics of diversity, but instead pose the value of diversity as exogenous. In addition, these theories are mostly concerned with investment in exclusive rather than simultaneous alternatives, in which case recombination is not feasible. Another important approach is classical portfolio theory, which also takes diversity and its value as fixed and given (Markowitz 1952, Sharpe 1964). In Section 3 these and a number of related formal approaches will be briefly reviewed and evaluated against the studied problem.

Finally, the focus on diversity and recombinant innovation brings us into the realm of evolutionary economics (Nelson and Winter 1982, Dosi et al. 1988, Andersen 1994, Potts 2000). Diversity is the key concept within evolutionary thinking, evolutionary computation, and evolutionary economics alike. It means a step away from traditional economics with its core assumption of representative agents. Giving attention to diversity requires adopting instead a population approach to describe agents and their strategies. The smallest population consists of only two elements, which will be the starting point for the formal analysis offered here.

The remainder of this paper is organized as follows. Section 2 discusses relevant aspects of diversity, employing insights from economics, biology, evolutionary computation and organization studies. Section 3 reviews the assumptions and insights of a number of model-based approaches that have been proposed to study investment decisions and the role of diversity in economic systems. Section 4 introduces the model of optimal, endogenous diversity with increasing returns to scale and recombinant innovation. Section 5 presents the results of numerical analyses performed with this model. Section 6 discusses policy insights. Section 7 concludes.

\section{Diversity}

In line with evolutionary biology as well as recent discussions on biodiversity loss and conservation, Stirling $(1998,2007)$ notes that diversity is a multidimensional concept. He proposes to characterize it by three dimensions or elements, namely variety, balance and disparity. Variety denotes the number of different technologies, processes, products, organizations, institutions or strategies in a population of elements. Variety can comprise 
identities (appearance), functions, or behaviors (knowledge, problem-solving capacity). Balance or equality relates to the extent to which one or more elements dominate in a population in terms of size or number (frequency). Disparity or dissimilarity refers to the degree of difference between elements in a population. Many indicators of diversity are available (Maignan et al. 2003, Stirling 2007). Stirling (2007) offers a very general formal framework and uses this to identify (implicit) assumptions underlying a number of wellknown diversity and inequality measures (e.g., Gini, Shannon, Simpson indicators). The three dimensions of diversity (variety, balance and disparity) may each affect innovation and selection and thus future diversity as well as benefits.

Diversity is the material upon which evolution works, and it affects both core processes of evolution, namely selection and innovation. Selection can realize a better outcome if it works upon more diversity. This is reflected in the famous theorem by Fisher (1930) which says that the greater the genetic variability upon which selection for fitness acts, the greater the expected improvement in fitness is. Indeed, selection (survival and reproduction) that builds upon a broader basis (greater diversity) can realize a higher performance and thus a higher average fitness of survivors (selected units) (e.g., Metcalfe 1994 and 1998). In addition, greater diversity means a greater potential for creative combinations. This has in the literature been addressed in various way, leading to notions like recombination or cross-over (in genetics and evolutionary computation), modular evolution (in biology, evolutionary computation, and technological innovation studies), and spill-over (in economics of technological change).

Modular evolution can be seen as a generalization of the older recombinant (or crossover) and symbiosis concepts, and it denotes that complementary units combine to a previously nonexistent unit with new, emergent features (Schlosser and Wagner 2004, Watson 2006). Modular evolution is the source of radical innovations in both natural and social-technological history (Maynard Smith and Szathmáry 1995, Mokyr 1990, Henderson and Clark 1990). Technological examples are of all times: pc and battery combining into a laptop, and watermill technology and sail concept leading to a windmill. Spill-over is less ambitious and means that one idea, behavior or technology inspires a change in another, which then improves in terms of functioning (fitness, productivity). Potts has proposed a kind of extension of the notion of modularity, namely 'hyperstructure'. This denotes that products, techniques, organizations and institutions can be regarded as nested networks of connections. Innovations involve new connections, while major innovations would mean a new nesting or an (emergent) higher level (i.e. a more complex hyperstructure).

Innovation through recombination is a common approach in evolutionary computation, and has proven to be effective (Eiben and Smith 2003). Note that here recombination, like in biology, usually involves two inputs ('parents'), analogous to the 
crossover of chromosomes during meiosis in diploid, sexual organisms. In social, economic and cultural applications, however, the restriction to two inputs is unnecessary, as recombination is not restricted by a sexual type of process (two parents). Instead, one can expect regular combinations of more than two inputs, implying a wider spectrum of innovations and a greater opportunity for radical innovation. Think of recent mobile phones that combine sms, email, internet, music and camera (even photo and video).

Supporting or increasing diversity and especially maintaining the element of balance in diversity has an additional benefit, namely avoiding rapid or easy lock-in. Search for shortterm efficiency or even net present value optimization often results in increasing returns to scale through network and informational externalities and imitation at the demand side or economies of scale in production, learning-by-doing, and technological standardization at the supply side. In terms of diversity this means that one or only a few alternatives survive. This is known in the literature as path-dependence and the extreme case of a single surviving, dominant alternative as lock-in. ${ }^{1}$ Not necessarily the best alternative gets locked-in. This is due to a combination of coincidence ('historical accident') at an early stage of market development and positive feedback or self-reinforcement due to the presence of the various increasing returns on demand and supply sides (Arthur 1989, Foray 1997). In the present framework, one could interpret such lock-in as representing a minimum of potential diversity.

An inevitable final question is whether one should strive ultimately for a dominant alternative (technology)? Perhaps not, as one might want to guarantee a minimum level of diversity of alternatives as a sort of insurance or resilience in the face of unforeseeable economic, political or environmental changes and future problems. Carroll and Hannon (2000) point at an old evolutionary principle, namely that in an uncertain world an internally diverse system (population) is more likely to respond appropriately to external changes than a homogeneous system. Similar ideas are found in the literature on resilience, adaptive management and policy experiments (Walters 1986, Gunderson and Holling 2002, Rammel and van den Bergh 2003). Resilience was originally proposed as an extended ecological stability concept that stresses ecosystem flexibility in the face of both external shocks and gradual, slow change (Holling 1973). Two types of resilience are commonly recognized, namely the time necessary for a disturbed system to return to its original state (Pimm 1984) and the disturbance that a system can absorb before moving to another state (Holling 1986). Resilience has further been proposed as a specific interpretation of (environmental) sustainability (Common and Perrings 1992) and has also been used to address the internal functioning of social-economic systems (Levin et al. 1998). Resilience is mostly associated with an insurance and precautionary perspective on the role of diversity, but is not necessarily

\footnotetext{
${ }^{1}$ If an external environment is heterogeneous (i.e. adaptation is to a local environment that is isolated to some degree), different technologies might adapt to each of the resulting niches.
} 
inconsistent with regarding diversity as a source of recombination. Stirling (2004) offers a more elaborate discussion on the potential link between diversity and resilience.

\section{Inspiration from existing economic and evolutionary models}

Before developing a set of evolutionary models incorporating the value of diversity, it is useful to examine what formal models and related insights the literature already offers. Several approaches are available to address investment decisions in the face of alternative options, namely option value theory, real options (investment under uncertainty) theory, porfolio investment theory, and a few other less influential approaches.

Option value theory has stressed the existence of options in the face of uncertainty about benefits and irreversible or even irrevocable change (e.g., deforestation, soil pollution, ecosystem destruction, biodiversity loss, or extreme climate change). A founding paper is Weisbrod (1964). Krutilla (1967) argued that decisions made in private markets do not lead to socially desirable use, allocation and conservation of nature and natural lands. He draws attention to the complex relationship between nature conservation, irreversibility and relative values. These values cover uses such as outdoor recreation, education and science alike. Influential innovations of this paper are the notions of option demand and value. Important follow-up studies formalizing this problem are Fisher et al. (1972), Arrow and Fisher (1974), Henry (1974) and Epstein (1980). This literature suggests that under certain conditions irreversible developments should be avoided or postponed when better information can be obtained. The models used generally consider two exclusive alternatives, namely development and preservation, and restrict the problem to a two-period setting. The notion of quasi-option value is derived from this approach. It reflects the value of extra information obtained by waiting (i.e. not developing or investing but preserving the current state) in the face of irreversibility and uncertainty. The Krutilla-Fisher algorithm is one approach to change standard cost-benefit analysis to include irreversibility of development, namely by treating foregone benefits of preservation as opportunity costs of development (for a good account, see Porter, 1982).

Closely related are theories of investment under uncertainty (Pindyck 1991, Dixit and Pindyck 1994) and real options theory (Luehrman 1998). These theories have links with options pricing theory in financial economics (Black and Scholes 1973), where an option is defined as the right to make a financial investment decision in a certain time interval. A real option then is the right to make a concrete business decision, often an investment in a project or property, that involves physical, tangible assets such as equipment. Real options theory takes account of the monetary value of (managerial) flexibility to adapt earlier decisions in the face of uncertain external developments. A number of real options can be distinguished, namely postponement of investment (until market conditions are better), expanding (growth) 
or downsizing, flexibility (abandoning other projects in the future), an exit option (cancelling a project), learning (research and development), and mergers and acquisitions. Taking into account real options can significantly change the valuation of investments as derived from a traditional net present value approach. Pindyck (2000) examines the notion of optimal timing of environmental policy using real options theory. Coggins and Ramezani (1998) and Fisher (2000) shows that option value theory is equivalent with the theory of investment under uncertainty, which is disputed by Aslaksen and Synnestvedt (2004).

Portfolio investment theory developed by Markowitz (1952) and elaborated in the capital asset pricing model by Sharpe (1964) is the more classical approach to study diversity. It focuses on mean-variance trade-offs on an efficiency frontier involving multiple securities. The main insight was that investors should be focused on selecting well-balanced portfolios instead of individual securities. This portfolio theory is not dynamic, although temporal effects may be included in the valuation of securities.

Of the other approaches to deal with alternative options and irreversibility, the following deserve attention. Hong and Page (2004) develop a model to examine the role of diversity in the context of groups of intelligent, problem solving agents. They find that a group of randomly selected agents outperforms a group consisting of the best-performing agents. Greater individual ability of the latter is more than offset by the lack of problemsolving diversity at the group level. Garcia et al. (2003) develop a systems dynamics model of the decomposition of R\&D efforts into explorative and exploitative activities and identify four relevant factors: resource availability, exogenous competition, aging of knowledge bases, and adaptive capacity to the environment. Gollier et al. (2000) formalize the rationality of adhering to a precautionary principle (i.e. keeping options open). Young (2001) replaces expected utility maximization by Shackle's (1949) approach, which pays attention to potential surprise and uncertainty-induced demand failures. Krysiak and Krysiak (2006) present an analysis of uncertainty and irreversibility by demanding that an allocation is envy-free, leading to an interpretation of sustainability as an intertemporal distribution in which no future generation prefers to live at an earlier point in history. In addition, sustainability at the level $p$ can be defined as equivalent with future generations with a small probability $p$ being willing to live earlier in time. In this way the authors can avoid the fundamental problem of interpersonal or intergenerational welfare comparisons. In addition, with regard to climate change particularly, irreversibility of investment has received attention as well (e.g., Birge and Rosa 1996, Kolstad 1994, Ulph and Ulph 1997).

A theoretical framework based on genetic distance to study optimal diversity was proposed by Weitzman (1992) and perfected by Weitzman (1998a), with application to biodiversity in mind. He studies the problem of protecting biodiversity under a limited budget constraint. A criterion for setting priorities among biodiversity-protecting projects is based on 
the assumption that the loss of biodiversity due to the extinction of a species is exactly equivalent to the distinctiveness of that species. The latter is defined as the genetic distance between species. Baumgärtner (2004) and Van der Heide et al. (2005) have extended this approach with ecological relationships, which may lead to other policy advice. For a dynamic approach that combines biodiversity with resource and ecological dynamics, see Swanson (1994).

Finally, a formalization of polarization, a specific form of diversity, is proposed by Esteban and Ray (1994). They argue that polarization is important for the study of social conflict and that it is fundamentally different from inequality. For example, a polarized system may be consistent with low inequality as measured with traditional indicators, such as a Lorenz curve (or Gini coefficient).

All of the studies mentioned above can be seen as treating diversity in an exogenous way, meaning that diversity does not affect system dynamics and its valuation, while diversity itself does not change over time, except in the sense that an option may be foreclosed or maintained. The application to environment and resources usually also involves a problem in which there is asymmetry of options: development or exploitation of a resource excludes its conservation, whereas conservation implies the future option of development. The issue of interest in this paper is subtly different: alternative options exist alongside and can influence each other (spillover), or possibly be combined to generate new options (i.e. more diversity).

The previous studies do not include interaction between options (spill-over, recombination). Recombinant growth as studied by Weitzman (1998b), Olson and Frey (2002) and Tsur and Zemel (2006) captures recombinant innovation. Weitzman presented a formal model in which the number of new combinations is a combinatorial function of the number of existing ideas (he speaks of "hybridization of ideas"). He shows that if this number were the only limiting factor in knowledge production, super-exponential growth would result, which evidently does not conform to reality (but perhaps we are not managing diversity well enough). Combining ideas and technologies, however, requires R\&D efforts and outlays that use scarce financial, labor and capital resources. Weitzman assumes a constant (exogenous) share of output to be allocated to $\mathrm{R} \& \mathrm{D}$, which results in balanced longrun growth. In other words, the limit to growth is not due to a limited number of recombinations or new ideas but due to limited $R \& D$ resources. While Weitzman provides a foundation of growth in recombinant innovation, he does not derive rules for optimal recombinant growth. In addition, Weitzman's approach does not really provide a micro foundation, as individual alternatives that may recombine are not explicitly described. Instead, a function to represent the number of different binary pairings and a "binary recombinant expansion process" are defined. This involves some level of aggregation in the description, or a black box. Tsur and Zemel extend Weitzman's model with an endogenous 
growth component by making R\&D decisions endogenous and find that Weitzman's constant $R \& D$ output or income share is consistent with optimal long run growth. Olson and Frey connect Weitzman's recombinant growth with Schumpeter's view of the entrepreneur as innovating by combining existing ideas or technologies in a convex way. They demonstrate that the resulting combinatory process is constrained by five factors: convexity implies exhaustion of technological opportunities, the cost of combining increases with distance (disparity) between originating ideas, combining ideas that are technologically close is rational (i.e. best for profits), social acceptance constrains or prohibits certain combinations of ideas, and a ruling technological paradigm limits the scope for continuing combining; they suggest that, in fact, a very restrictive technological opportunity set may stimulate a paradigm change.

Within evolutionary economics several models are worth mentioning here. The $N K$ complexity model (Kauffman 1993, Frenken 2000) stresses the combinatorial nature of design space. Here $N$ denotes the number of elements (each with diversity of values/alleles), while $\mathrm{K}$ is the number of connections between elements (complexity measure). A fitness or performance function can be defined over the design space. This has been applied, among others, to the steam engine to analyze which possible designs have emerged in reality and which ones (including hypothetical ones) (could) have performed well (Frenken and Nuvolari 2004). Based on the idea that transitions are best perceived as involving multiple transition steps, Frenken has recently used this model to examine how one can best move in complexity space from one design to others, taking into account irreversibility and flexibility (not foreclosing options, including new evidence, and changing preferences), uncertainty and the theoretically best performing alternative (the end goal). This leads to a trade-off between flexibility, best (efficient) end point, and shortest route (cost of intermediate steps). He illustrates the approach with an application to possible future car systems (Frenken 2007).

Munro (1997) extends the standard, general model of optimal use of a renewable resource with pesticide use that exerts a negative intertemporal externality due to genetic selection. He illustrates this for an insecticide that raises the fitness of resistant insects relative to their susceptible competitors. The perspective can be that of an individual farmer or, more realistically, a policy maker trying to understand the optimal dosage of insecticide in a region. Some main insights obtained are as follows. The traditional planning solution can be considered to be myopic as it does not anticipate evolution. Instead, optimization under perfect foresight about evolutionary consequences of insecticide use gives the fully optimal plan. Comparison of myopic and fully optimal plans shows that under the latter the size of the pest population is lower, while the proportion of susceptible individuals is higher. For a higher discount rate the optimal pesticide use will be higher as well so that resistance will increase. As a corollary, under myopia, investment in $R \& D$ on new pesticides will be 
relatively high. This model only addresses selection (irreversible loss of genetic diversity), excluding innovation.

Iwai (1984) presents a general evolutionary-economics model that combines innovation and selection through imitation. In a way, this is the archetype evolutionaryeconomic model, as it provides a rather complete description of increase (innovation) and decrease (selection) of diversity. Iwai refers to these as disequilibrating and equilibrating forces, respectively, that give rise to collapsing (narrowing), exploding (broadening) and shifting probability distributions of a certain technological feature. Analysis with the model shows that the technological distribution in an industry will never reach equilibrium because of continuous innovation. This can be opposed to evolutionary game theory, in which equilibrium is a general outcome, which is due to a complete focus on selection processes (i.e. an omission of regular or structural innovation). Saviotti and Mani (1995) offer a similarly general model based on replicator dynamics that describes the relation between variety and competition. They distinguish between inter- and intra-technology competition and show that the variety of a system can increase only if intra-technology competition is more intense than inter-technology competition. Moreover, new technologies can emerge only if incumbent technologies face weaker competition from new ones than from other incumbent ones.

Finally, the balance of exploration and exploitation has been approached with theories of evolutionary and adaptive organizations (Hannan and Freeman 1977 and 1989, Levinthal and March 1981, Lewin et al. 1999). The motivation for this approach is that a wide diversity of organizational structures can be observed in reality. This diversity applies to various characteristics, including form (e.g., line-staff, matrix, flat), elements (e.g., R\&D, production, sales) and connections (e.g., formal, informal). Hannan and Freeman (1989) identify two types of theories of organizational change that involve adaptation. The first comprises selection (population adaptation) theories, which assume that diversity arises mainly from new organizations, as existing organizations adopt a structure early on and rarely change it because of rigidness. Alternatively, individual adaptation theories assume that individual organizations can respond and adapt to environmental changes, threats and opportunities.

\section{Optimizing diversity given recombinant innovation: a model}

An explorative model of diversity is developed here. It focuses on recombinant innovation, that is, innovation through combination of existing alternatives so that multiple options are modeled. Cumulative investment in two available options is modeled to keep the analysis simple. A diversity indicator is constructed with three inputs, namely variety, balance and disparity. The emergence or innovation of a third option is probabilistic and depends on diversity as measured by the diversity indicator. This type of innovation can be regarded as a 
process of spill-over, as in the case of thin film technology being used in photovoltaic technology to convert solar radiation into electricity. Alternatively, innovation here can be considered as a modular process in the sense that the two original options come together as components in an emerging technology, such as batteries and personal computer technologies have been combined into laptops. The approach here is not only consistent with innovation of isolated products with a modular structure (e.g., machines, vehicles, consumer electronics, buildings) but also network (service) markets where modularity often takes the form of complementary products (e.g., hardware and software, computer and internet). Moreover, the relevance of the proposed approach is not limited to spillovers between technologies. Murray (2002) illustrates with the case of tissue engineering that important innovations in both technology and science can accompany spillover of knowledge in either direction.

Direct benefits associated with the presence of each option depend on scale; in particular, there may be increasing or decreasing returns to scale (both on demand and supply sides, which are not separately described here, or remain implicit). As a result, optimal diversity based on maximizing total benefits can proceed by trading-off returns to scale and innovation benefits, both of which depend on the level of diversity. The model can be considered as evolutionary, in a very limited sense, as it describes a minimum population of two alternatives (technologies) while interaction between these can increase the number up to three alternatives. This is a very simple conceptualization but nevertheless a logical point of departure for a formal analysis of the mentioned trade-off.

Below we present the model equations. Note that the model is dynamic so that all variables have time subscripts. These are omitted to improve readability.

Investment in two available and one hypothetical option and resulting cumulative investment or capital stocks are as follows:

$$
\begin{aligned}
& d O_{1} / d t=I_{1} \\
& d O_{2} / d t=I_{2} \\
& d O_{3} / d t=P_{e} * I_{3}
\end{aligned}
$$

with

$I_{1}=a * I$

$I_{2}=(1-a) * I$.

Here $O_{i}$ denotes the cumulative production of option $i$, which can be interpreted as an indicator of cumulative knowledge about the respective technology. $I_{i}$ is investment in option $i$ (at time $\mathrm{t}$ ), and $a$ is a fraction denoting investment allocation $(0 \leq a \leq 1)$, the proportion of the 
investment budget (I) in year $t$ spent on option 1. Note that $a$ might be variable over time (i.e. have a time index as well), but for the analysis hereafter we consider only constant $a$ values over time. $P_{e}$ is the probability of emergence of a third option, which is explained below. To keep the model simple, it is assumed that there is no depreciation of technological knowledge or capital (in the case of pure knowledge, the preferred interpretation, one might argue that depreciation will be rather slow or negligible). The right hand side of the third equation represents the expected value of benefits associated with investment in hypothetical option 3 , based on uncertainty about the emergence of option 3 . The values of $I$ and $I_{3}$ are exogenous to the model, as the central problem is optimal diversity of options 1 and 2, or optimal allocation of investment between options one and two. Initial conditions for the three cumulative variables $\operatorname{are}^{2}$

$O_{1}(0)=0, O_{2}(0)=0, O_{3}(0)=0$.

Total benefits $B$ are the sum of benefits associated with each alternative, such as $B_{i}$ for option $i$ :

$B=B_{1}+B_{2}+B_{3}$

We are interested in the optimal (maximum) value $B(T)$, that is, the value of $B$ at some final time $T$ (time horizon), which in the next section will be the end of the simulation period. Returns to scale are formalized through the following benefit functions associated with each option at time $T$ :

$B_{l}(T)=O_{I}(T)^{s}$

$B_{2}(T)=O_{2}(T)^{s}$

$B_{3}(T)=\left(O_{3}(T) * D^{2}\right)^{s}$

Here $O_{i}(T)$ denotes the value of $O_{i}$ at time $T$. Returns to scale $s(s>0)$ in each of these equations reflect the presence of increasing returns on the production side (e.g., economies of scale, learning) as well as the demand side (familiarity, reputation). Applying $s$ to $O_{i}(T)$ means that the size of the option at time $T$, for example, the cumulative rather than static (per point in time) investment in an option up to time horizon $T$, is the basis for calculating the effect of increasing returns. This is done as returns to scale do not cover just static economies

\footnotetext{
${ }^{2}$ Setting initial values of the options equal to zero does not undermine the general character of the analysis, as the insights obtained in the next section would not alter with positive values of options one and two (reflecting their history before the initial time of the simulated period). Of course, option 3 cannot exist at the initial time.
} 
of scale in production but also dynamic learning effects over the entire period $[0, T]$. Note that the returns to scale apply to single options (1,2 and 3) and not to the total (sum) of the three options/technologies since returns to scale relate to separate market shares (demand and supply side) for each of these options. The inclusion of the quadratic term with disparity $D$ in equation 10 reflects a nonlinear effect that disparity between options 1 and 2 has on the benefits associated with option 3 (once emerging). These benefits increase more than linear with the level of disparity as higher values of disparity are assumed to imply more radical innovations, which in turn are associated with relatively high benefits.

Innovation occurs through combination of existing alternatives or spill-over, and the degree of diversity is affecting this process. Following Stirling (1998), diversity $\Delta$ is defined as follows:

$\Delta=0.5 * N * L * D$.

Diversity has three components, as discussed in Section 2, namely the number of alternatives $(N)$, balance $(L)$, and disparity $(D)$. Moreover, diversity is positively related to each of the components. The multiplicative form can be seen as consistent with the idea that different components of diversity can substitute for each other (in terms of the net diversity effect) but only up to some degree. As opposed, an additive form would assume perfect and limitless substitution, which seems a too extreme assumption to make. Fixed complementarity (or fixed proportions) as in a Leontief type of function seems also too strict. The multiplicative form can be seen as avoiding the extreme character of both alternative specifications. Another interpretation follows from the higher dimension diversity function (equation 14 in the next section), namely as variety weighted by a combination of balance and disparity (see Stirling 2007, Table 2).

Variety $N$ can take two values here, namely $N=1$ in case of specialization, and $N=2$ if there is (some) diversity. Balance $L$ is defined as

$L=\operatorname{Min}\left(O_{1}, O_{2}\right) / \operatorname{Max}\left(O_{1}, O_{2}\right)$.

This function assures that the more balance between cumulative investments in both options is realized, the higher diversity is. Stirling (2007) proposes an alternative specification, which shows the same qualitative behavior and which we will use later on as well (in equation 14).

Disparity will in the two option case later have a default value 1 so that the value of diversity $\Delta$ is then in the range 0 to 1 . Note further that since the inputs $O_{i}$ change over time, $\Delta$ is a dynamic variable as well. Finally, the resulting specification of $\Delta$ is consistent with core 
features (i) to (v) of a general diversity heuristic, as formulated by Stirling (2007). In particular, if $N=1$, then $L=0$, so that $\Delta=0$, which is Stirling's feature (i).

Next, the probability of innovation or emergence of a new, third option can be made dependent on the diversity index:

$P_{e}=p^{*} \Delta\left(D^{\alpha}\right), \alpha \geq 0$

More overall diversity in the system means a higher probability of recombinant innovation. Parameter $p$ is exogenous and can be interpreted in several ways. A first interpretation is that it reflects the nature of a particular technology or type of knowledge; for example, for some technologies or knowledge the likelihood of successful (marketable, profitable) innovations due to recombination of existing technologies or knowledge is higher than for others, which would be reflected by a higher value of parameter $p$. It seems that, for instance, ICT technologies are characterized by relatively many opportunities for recombination with other ICT components as well as traditional technologies (add-on components to cars, television sets, hifi equipment, kitchen equipment, microelectronics), explaining the wave of ICT related innovations since the early 1980s. A second, additional (i.e. not competitive) interpretation is that parameter $p$ can change over time, countries or again technologies due the differential effectiveness of human endeavors to produce innovations through recombination. This in turn depends on the regional-national innovation system, which covers such elements as the level of education, the organization of research (e.g., individualized, team work, isolated laboratories, dynamic networks), experience with research (a sort of $R \& D$ learning curve), public policy and institutions (tax and subsidy regimes, public R\&D), and users (see Lundvall 2007). A very fundamental factor here is formed by the collection of communication techniques and search methods employed for research. In this respect, the emergence of fast means of transport (car, train, plane), telegraph, phone, fax, printer, scanner, mobile phone, email, and the Internet (including electronic journals and sophisticated search engines like Google) can be seen as developments that have changed the fundamental conditions for communication and search of information, resulting in an increased likelihood of innovative combinations (i.e. a higher value of parameter $p$ ). The further integration and extension of multimedia and telecommunications means that this process has not yet come to an end (if it ever will).

Next, parameter $\alpha$ in equation 13 can be seen as reflecting a 'cognitive distance', such as the distance between knowledge or experts on options 1 and 2. On first thought, one might think that $D$ and $\alpha$ are proportional (i.e. a small (large) disparity automatically goes along with a small (large) cognitive distance). However, this is not necessarily the case, for example, as two options with large disparity may be associated with expertise that is bundled, 
for various reasons, be it historical coincidence, multidisciplinary education, or multiproduct firms. In fact, many fundamental innovations in science have been realized by researchers who have crossed disciplinary boundaries, thus in a way lowering the value of $\alpha$, resulting in an increase in the probability of recombinant success. In view of this, four possible combinations of disparity and cognitive distance need to be reckoned with, namely small or large $D$ and small or large $\alpha(2 \times 2)$.

Disparity $D$ has a double effect, indirectly (positively) through diversity, and directly (negatively) to reflect that it may be easier to combine things or enjoy positive spill-overs if the alternatives are not too far apart. Note that for $\alpha=1$ the direct and indirect effects cancel out so that disparity will not affect the probability of emergence of a new option. Parameter values in the diversity and probability function are such that $P_{e} \leq 1$ is satisfied. ${ }^{3}$ Note that innovation may be of a more uncertain, even surprising nature than exemplified in equation 13. This is not covered here, even though one may expect it to be relevant in the decision about optimal diversity. We will say more about this in Section 6.

The indicator of disparity as a dimension of diversity allows us to make a distinction (in interpretation) between gradual and radical innovations: recombining options 1 and 2 under low disparity would imply gradual innovation; doing the same under high disparity would mean radical innovation. Since disparity affects the benefits of the new option 3 (positively) as well as the probability of its emergence (negatively), the net effect on total benefits depends on the specific values of the parameters involved.

\section{Numerical analysis}

Here we present numerical results obtained with model. The time horizon is set at 20, which is sufficient to identify the dynamic effects of diversity (i.e. recombinant innovation and its benefits). The following values or ranges for parameter values and exogenous factors are used (ranges in fact indicate that parameters will be subject to sensitivity analysis). The total investment budget in each period for options 1 and 2 is $I=100$. Investment in the third option, which is not effective if this option does not emerge (i.e. if $P_{e}=0$ ), is set at a constant level $I_{3}=50 .{ }^{4}$ For the probability scale parameter the range $0 \leq p \leq 0.5$ is used, while the

\footnotetext{
${ }^{3}$ The model is consistent with both codified and tacit technological knowledge. In the first case, recombination will most likely occur through engineers that are specialised in different technologies exchanging or combining tacit knowledge about these. More balance will then mean more engineers in either technological area and therefore more opportunities to cooperate or exchange information. In the case of codified knowledge, a single individual will be able to combine knowledge about separate technologies. More balance may then go along with better accessibility and quality of codified information in either technological area, which in turn will enhance opportunities for successful recombination by a single researcher. Of course, codified knowledge is flexible in that it also allows recombinant innovation to follow the route of cooperation among individuals with different technological expertise.

${ }^{4}$ Investment in option 3 is only effective if this option (probabilistically) emerges. The model requires a value of this investment, but it is not useful to make it part of the investment allocation problem between options 1 and 2, as this would confuse the essence of the model: namely analysis of the problem of optimal diversity between options
} 
default value equals 0.1 . This, together with the maximum value taken by the diversity index $(=2)$ assures that the innovation probability will never exceed one. For the returns to scale the following range is used: $0.6 \leq s \leq 1.4$. The level of disparity has a default value equal to 1 and is varied in the range $[1,2]$. The direct effect of disparity on the emergence probability is set at a fixed value $\alpha=1$.

All subsequent results (graphs) plot relative total benefits over the entire period, that is, from 0 to time horizon $T$. Here, 'relative' denotes that the total benefits $(B(T))$ have been normalized using as a normalization factor the value of the total benefits when the allocation factor $(a)$ is equal to 0 . As a result, in all the graphs shown hereafter the curves intersect in the left corner point (where $a=0$ ), and in this point the value of the relative total benefits is equal to 1 . Often, intersection of the curves in a single point can also be observed in the right corner, where $a=1$. This is due to symmetry of the problem. Only in the final results (Figure 7) does intersection in a single point not occur for $a=1$ as here symmetry is purposefully foregone.

Figure 1 shows the relative total benefits over the entire simulated time period for different investment allocations (horizontal axis) and for returns to scale varying from 0.6 to 1.4 (different curves). The results show that in the case of decreasing and constant returns to scale, symmetric or balanced diversity (i.e. equal investment in the two options) is always optimal, while for sufficiently increasing returns to scale specialization or focusing is more attractive. The first two results are quite robust as illustrated by Figures 2, 3, and 5, while the last result is not robust (depends on specific parameter values), as shown in Figure 4 below.

\section{[Insert figure 1 around here]}

Figures 2 to 4 present the effect of different probability factors on relative total benefits. For decreasing (Figure 2) and constant (Figure 3) returns to scale, a higher probability of recombinant innovation just makes diversity a more evident choice from the perspective of optimal total benefits. The reason is that both figures 2 and 3 show that diversity benefits increase relative to specialization (corner solution) benefits. Symmetric diversity (equal investment in the two options) is optimal in both cases, which is the result of symmetry in the model (i.e. no difference between options 1 and 2 in terms of benefits, returns to scale effects, and disparity). Optimality of symmetric diversity becomes more pronounced for higher probability factors as the diversity benefits through recombinant innovation increase due to the balance component of diversity. The lowest positioned curves $(p=0)$ in both figures show

1 and 2 taking into account the emergence of option 3. An allocation of total investment among three options would only be relevant for the research question if as a result a fourth option could emerge as a combination of the 
that without any possibility of recombinant innovation under constant returns to scale (figure 3 ), there will be no difference in benefits between alternative investment allocations (so that one will be indifferent between these), while under decreasing returns symmetric diversity is hardly more attractive than nearby positions on the curve (i.e. the symmetric diversity optimum becomes much less pronounced). In fact, if uncertainty about the future were taken into account, one might result to be quite indifferent between allocations in the $a$-parameter range 0.3-0.7 because of the small differences in benefit terms.

\section{[Insert figures $2-3$ around here]}

Increasing returns to scale (Figure 4) in principle favor specialization (i.e. concentration of investments in one alternative), but this is countered by increasing the probability factor of recombinant innovation, which results in an improved pay-off of diversity. In other words, there are two counter forces at work here, namely increasing returns to scale and the chain diversity-recombination-innovation. These two forces attain different balances or net effects in benefit terms on the range of investment allocations. As a result, a three-modal pattern appears in Figure 4 for higher probability factors. This figure shows that for a value of parameter $p=0.8$, symmetric diversity $(a=0.5)$ provides the highest total benefits, that is, higher than in the cases of extreme specialization (investment allocation equal to 0 or 1 ). Note that the shape of the curve can be interpreted as the existence of three local optima. If these local optima have the same total benefit value, one will be indifferent between them. However, this is a very unlikely situation, since for most combinations of parameter values either the two specialization allocations ( $a=0$ and $a=1$ ) will have the highest value (two global optima, again due to symmetry of options 1 and 2 ) or symmetric diversity ( $a=0.5)$ will have the highest total benefit (i.e. one global optimum, as in the upper curve of Figure 4). From an empirical perspective, the case of increasing returns to scale is least trivial and deserves special attention to see which counter force is dominant. Evidently, this would require estimation of the values of the parameters involved.

\section{[Insert figure 4 around here]}

In line with the interpretations of the parameter $p$ in the previous section, we can regard the patterns in figures 2 to 4 as reflecting changes in $p$ over time due to individual and organizational learning in the $\mathrm{R} \& \mathrm{D}$ process (public or private), or alternatively as a comparison of regions/countries (or technologies) that show different propensities of

first three. However, the investment in this fourth option would then need to be set exogenously, which just shifts the problem. 
recombinant innovation due the particular features of the regional/national innovation system (or the technology). For example, according to the first interpretation, a larger $p$ might denote the emergence and increasing influence over time of telecommunications (phone, fax, email, Internet, search engines, electronic journals) on $R \& D$ activity in general, and in line with the second interpretation, it might reflect that R\&D in some economic sectors is less sensitive to the influence of Internet than other sectors. The general implication is that depending on the returns to scale, according to the intertemporal interpretation of different values of $p$ the role of diversity and the optimal level of diversity may change over time, while according to the inter-sectoral or inter-regional/county interpretation, diversity may matter more or less for some than for other sectors or countries.

One can further identify a value of diversity associated with each of the curves in figures 1 to 4 . This notion can be defined as the difference between total benefits at investment allocation $=0.5$ (maximum diversity) and investment allocation $=0$ or 1 (no diversity). In some cases (figures) this diversity value is positive while in others it is negative, evidently depending on whether diversity is optimal in total benefit terms or not.

Next we turn to disparity. Figure 5 and 6 show results for different levels of disparity in the range [1-2]. It is shown that under constant returns to scale, more disparity means that diversity pays more off (Figure 5). Under increasing returns to scale (Figure 6) this effect gives rise to a pattern similar to the one in Figure 4. Note that only with sufficient balance (investment allocation between 0.4 and 0.8 ) does the effect of disparity become visible. Of course, this depends on the value (or explored range) of disparity, and it is not clear in general whether this is realistic from an empirical perspective. Measurement of disparity in practice could resolve this but is likely to be difficult.

\section{[Insert figures 5 and 6 around here]}

A final analysis offered concerns heterogeneous disparity values. For this purpose we need to change the set-up of the model slightly. First, we need initially (at least) three options and the probabilistic emergence of a fourth option, since with only two initial options one has only a single disparity (between options 1 and 2) and therefore no opportunity to arrange heterogeneity of disparity values. With three options one will have disparity values for the difference (or distance) between options 1 and 2, 1 and 3, and 2 and 3, three different disparity values. To retain the focus on diversity of two options ( 1 and 2), we add to these a third, exogenous option. The exogenous character of this additional option means that the allocation problem and thus the focus on diversity of options 1 and 2 does not alter. However, adding a third option means that the specification of the diversity function used before is problematic. Instead, we apply therefore a more general (but also more complicated) diversity 
function, as proposed by Stirling (2007): $\Sigma_{i} \Sigma_{j \neq i} d_{i j} f_{i} f_{j}$. Here $d_{i j}$ is disparity between option $i$ and $j$, and $f_{i}$ is frequency or share of option $i$. In the present case $f_{i}=O_{i} /\left(O_{1}+O_{2}+O_{x}\right)$ so that the diversity function takes the following form:

$$
\Delta=d_{12} * O_{1} * O_{2} /\left(O_{1}+O_{2}+O_{x}\right)^{2}+d_{13} * O_{1} * O_{x} /\left(O_{1}+O_{2}+O_{x}\right)^{2}+d_{23} * O_{2} * O_{x} /\left(O_{1}+O_{2}+O_{x}\right)^{2}
$$

Note that option 3 is denoted by a subindex $x$ to reflect the exogenous nature of this option. We set the extra exogenous option $O_{x}=1000$ (i.e., this option is constant over the entire simulation period) to realize a magnitude that is conform average investment in options 1 and 2 over 20 time periods being equal to 1000 (i.e. $20 * 100 / 2$ ). To control model complexity, the direct effect of disparity on the innovation probability is omitted (i.e. we set parameter $\alpha=0){ }^{5}$

Results for heterogeneous disparity values are shown in Figure 7 for constant returns to scale. A few remarks are in order. A methodological one is that the curves are differentiable as opposed to the ones in the previous graphs. This is due to the new diversity function. Indeed, the specification of the balance function in equation 12 caused nondifferentiability in $a=0.5$, as can be seen in figures 1 to 6 . The symmetry in the bottom two curves results from equal disparities $d_{13}$ and $d_{23}$, while the higher of these curves is explained by the higher value of $d_{12}$, which increases the overall diversity value and as a result the innovation probability and derived expected benefits, except where there is no diversity (therefore the curves intersect in the corner points). More interesting are the asymmetric optima in the two top curves. These are due to the asymmetric distance of options 1 and 2 to option $x$. The lowest of these curves is monotonically increasing, meaning that pure specialization in option 1 is optimal (no diversity). Note that this is under constant returns to scale and entirely due to $d_{13}$ being larger than the other disparity parameters. Thus, with constant returns to scale heterogeneity of diversity can lead to specialization being optimal. If, however, the value of disparity $d_{12}$ is subsequently increased (from 1 to 2), the upmost positioned curve is obtained. This curve has 0.7 as an optimum value, which means (asymmetric) diversity with a bias towards option 1 . This result can be seen as a balance between opposing forces exerted by disparity $d_{12}$ and disparity $d_{13}$.

Thus, in addition to the specialization (regardless in which option) and symmetric diversity (perfect balance) as optimal solutions identified in the previous analyses (figures 16), with heterogeneous disparity two other type of solutions arises, namely pure specialization in one specific option and asymmetric diversity (imbalance). One can understand the difference between these latter two results, associated with the two highest curves in figure 7 , as follows. If $d_{12}$ has a low value (1) then options one and two are very near to each other so

\footnotetext{
${ }^{5}$ For three instead of two options a different, more general specification of this effect would be needed.
} 
that the difference in distances between options 1 and 2 to option $x$ matters much for recombinant innovation; that is, such innovation will be most likely or effective if 1 and $x$ are combined since $d_{13}>d_{23}(2>1)$. In other words, specialization in option 1 is optimal. If then $d_{12}$ attains a higher value (2), recombination of options 1 and 2 becomes a more likely outcome as well so that the value of investing not only in option 1 but also a bit in option 2 (asymmetric diversity) is optimal. Here, one in fact benefits from the availability of multiple viable recombinations $(1+2,1+3$, and $2+3)$, together making the likelihood of any recombinant innovation higher.

\section{[Insert Figure 7 around here]}

Finally, since we perform a dynamic analysis, a word on discounting is in order. Discounting implies that the future is perceived as less important by the decision-maker than the present. This holds for investments in both a single option and diversity of investments. Discounting was found not to affect the pattern of relative total benefits much. A possible explanation is that an expected value approach is used here to calculate the effect of probabilistic innovation on benefits, which results in a uniform distribution of impacts of diversity over time. One would expect that if diversity pays off only or especially in the very long run, then the more one discounts the future the less diversity would pay-off (in relative terms). Either a stochastic approach or one that includes the effect of size of investments on the innovation probability could realize such an influence of time horizon and discounting. Note, finally, that whereas the model excludes depreciation of invested capital in each option, inclusion of discounting might be interpreted as such. Of course, depreciation might be very slow if cumulative investment in an option is interpreted as a stock of knowledge rather than physical capital.

\section{Policy implications}

What are the policy implications of the findings of the previous analysis? For this purpose we have to examine the conditions under which each of the four solutions is optimal: pure specialization (no diversity) regardless in which option, pure specialization in one specific option, symmetric diversity (perfect balance), and asymmetric diversity (imbalance). The model parameter conditions associated with each type of optimal diversity may provide clues for policy and management. The immediate role of the government is to stimulate that at the societal level, at each point in time, diversity is such that an optimal trade-off between scale and innovation benefits results. A more fundamental role of the government is to manipulate the innovation parameters through adequate policies. The two core parameters are the probability factor, which co-determines the probability of successful recombination of 
existing technologies, and disparity, which reflects the difference between combined technologies.

In particular, a government could increase the probability factor by stimulating technologies that can be easily combined into a new technology, notably by striving for modular technologies since this allows the easy substitution or exchange of modules, resulting in an increase in the number of potential innovative combinations. Moreover, as illustrated by Watson using evolutionary computation, modules can be seen to represent preadapted (or preselected) units that allow faster and more likely evolutionary progress as well as a greater degree of complexity than is possible with gradual, non-modular evolution (see also Birchenhall 1995). Thus, modularization can increase the benefits of variety through realizing higher recombination probabilities and more radical innovations.

The notion of modularization opens up the debate on the setting and appropriability of standards (David and Greenstein 1990, Besen and Farrell 1994). Indeed, standards at the product, technology or component (module) level become less desirable when they go at the cost of opportunities for recombinant innovation. Governments might require fewer standards or implement policy to avoid the spontaneous or early emergence of certain standards (i.e. competition between standards according to Besen and Farrell) unless standards are such that they do not hamper or even facilitate recombinant innovation (i.e. competition within a standard according to Besen and Farrell). Similar policy considerations are at stake when addressing the risk of inefficient lock-in, so now there is one more reason to worry about standards.

Policy may try to raise the value of disparity between technological options to increase innovation benefits, notably through radical innovations. For this purpose, governments could use their tool of public investment in R\&D and assure that niches with 'deviant' technologies emerge or survive. In particular, governments might promote disparity by funding risky R\&D and by facilitating the creation of technological niches (Schot and Geels, 2007).

A general policy advice emanating from this study is that one should cherish ones failures and innovative wastage. Striving for specialization, focus and false certainty about efficiency (i.e. short term cost-effectiveness) hampers evolutionary progress. This implies that decisions informed by short-term cost-benefit or cost-effectiveness analysis excluding recombinant innovation may be detrimental to the system in the long run. A balance between short term efficiency and diversity needs to be arrived at. The precise balance is likely to depend not only on the factors discussed and modeled here, but also on the degree of uncertainty about innovations: the larger the uncertainty, the more diversity may be needed. This follows directly from adding the insurance to the recombinant perspective on diversity.

Notice further that diversity choices might take the scale and extent of a system into 
account. The reason is that maintaining a specific level of diversity may be costlier the smaller is the scale (e.g., a city or region). With a very large system scale (e.g., a country, continent or the world) there possibly is more room for simultaneously enjoying scale advantages and diversity benefits so that the conflict between scale and diversity becomes less pronounced. The latter partly depends on whether or not scale advantages and diversity benefits are subject to diminishing returns.

The foregoing policy insights should be judged in a broader context innovation and investment policy analysis. A fairly large literature offers a variety of considerations, based on evolutionary economics, notably neo-Schumpeterian innovation theories and a number of other approaches (e.g., Nelson and Winter 1982, David 1986 and 1987, Freeman 1987, Dosi et al. 1988, Nelson 1993, Metcalfe 1995, Cantner and Pyka 2001, Pelikan and Wegner 2003, Witt 2003, Dopfer 2005, Sartorius and Zundel 2005). A shortcoming of many of these policy discussions is that, whereas the positive side of the analysis is clear (e.g., grounded in evolutionary or neoclassical economics), the normative side is implicit or even absent. As a result, policy suggestions are not always well founded. Sometimes it seems just to be assumed that more innovation and diversity are automatically good for society, as if they have no costs, while in other cases the benefits of diversity are completely overlooked (as discussed in Section 1). Either approach represents an extreme viewpoint that is hard to defend as a general model. The conceptual model proposed in the current paper was precisely aimed to fill this gap. Even though it may not be complete in its description of reality, it nevertheless provides a concrete starting point for theorizing about, and empirical analysis of, innovation policy from the angle of diversity.

\section{Conclusions}

A technological path that contains just a few very efficient (i.e. low cost or quick payback) options may seem very attractive in the short run, but ultimately, in the long run, it provides a

narrow basis for selection to act upon. It can moreover slow down innovations as few innovative combinations and spill-overs will occur. Both negative impacts of limiting diversity (on selection and innovation) will restrict potential progress of a system in the long run.

The central message of this paper is threefold. First, diversity, irrespective of whether relating to technologies, behaviors, organizations or institutions, needs to be addressed as changing and endogenous. Second, diversity allows for recombinant and even modular innovation, which possibly represents its most important benefit. This role of diversity is different from the more traditional perspective on diversity as an insurance against unforeseen events or changes in the external environment. Third, diversity is to be seen as an investment rather than a cost (i.e. associated with not only costs but also benefits). From an 
evolutionary-economic perspective, evolutionary progress due to diversity can be translated into economic benefit terms. The essential trade-off that appears then is between the benefits and costs of diversity, or between evolutionary progress benefits (much diversity and thus recombinant innovation) and increasing returns to scale (specialization, i.e. little or no diversity). Optimizing this trade-off gives an optimal level of diversity.

The literature that links diversity to investment choice, irreversibility and uncertainty was reviewed, where it was noted that many and very different approaches exist. None of these, however, combines a treatment of diversity as endogenous and dynamic with the mentioned cost-benefit trade-off to determine optimal diversity. Nevertheless, various interesting suggestions emerge from this literature.

An own model of optimal diversity was then proposed. It takes as a starting point the problem of allocation of an investment budget between two alternative options. Based on this, a diversity indicator was constructed involving three dimensions, namely variety, balance and disparity. The level of diversity probabilistically determines recombinant innovation or emergence of a third option. Next, total benefits over time for the three options are influenced by returns to scale (increasing, constant or decreasing). The resulting model can be regarded as representing a first effort to capture optimal diversity as the trade-off between increasing returns to scale associated with each option and the benefits of recombinant innovation resulting from diversity.

It is found that with decreasing or constant returns to scale, maximum diversity (equal investment in both options) is optimal. However, possibly reality is generally better characterized by increasing returns to scale. The model shows that in this case diversity becomes attractive only if the (emergence) probability factor of recombinant innovation is sufficiently large. Diversity then pays off if it is sufficiently high, as a higher diversity implies a higher emergence probability. In addition, more disparity increases the value of diversity and can make diversity attractive in the case of increasing returns. The results indicate four types of optimal diversity under various conditions: complete specialization (no diversity) regardless of which option, complete specialization in one specific option, symmetric diversity (perfect balance), and asymmetric diversity (imbalance). The second and fourth solutions require heterogeneous disparity. The parameter conditions under which each type of optimal diversity arises may provide clues for empirical testing and application to policy of the results. From an empirical perspective, the case of increasing returns to scale is perhaps most interesting as two counter forces are at work and one would like to know which ultimately dominates.

A number of general policy lessons were derived from the analysis. An immediate role of the government is to stimulate public investments, at the societal level, where diversity is always in line with an optimal trade-off between scale and innovation benefits for society 
as a whole. A more fundamental role of the government is to manipulate the innovation parameters through adequate policies. In particular, it could stimulate the development of modular technologies that allow many innovative combinations. Setting or spontaneous emergence of standards is not only relevant from the perspective of the risk of lock-in, but also will need to take consequences for recombinant innovation into account. The latter is likely to depend on the particular technology at stake. Policy might further stimulate radical innovations by raising the disparity between technological options, notably by directing public R\&D at 'deviant' technologies and by funding risky R\&D. Next, the larger is the uncertainty about a recombinant innovation, the more diversity may be required along an optimal path. Finally, coordination of strategic technology policy between different countries might reduce the conflict between scale and diversity since in effect the total volume of all innovation and investment activity is then enlarged.

It is worth noting that the results obtained here do not seem to require that recombination is the only mechanism of innovation. The fact that there is non-recombinant innovation as well does not deny the benefits of recombinant innovation and therefore of diversity. This, however, leads to an interesting side question, namely whether all innovation is of a recombinant nature. As already argued by various earlier writers (e.g., Schumpeter 1934, Weitzman 1998b), it is difficult to imagine an innovation that cannot be cast in terms of combining things, regardless of whether it is a new idea, a new product, a new music style (Geels 2007), a new technology, or a new organization. In a modern economic context this is certainly true as innovations are the outcome of cooperation or at least interaction between many researchers, both in private companies and universities, and cooperation implies recombination (which is not the same as to say that recombination requires cooperation; probably as much it needs isolation and competition). Even a so-called 'spontaneous mutation' in a gene or technology is just an easy label for a black box that once opened may appear to be a combination of factors.

Evidently, the model presented here offers no more than a starting point for examining optimal diversity. It is easy to identify directions for further research. Instead of an expected value approach one might model innovation as a stochastic process (e.g., as the emergence of a viable recombination with a dichotomous probability 0/1). Monte Carlo experiments can then be used to provide average outcomes for the model system. Another extension would be to let the emergence probability depend also on the size of cumulative investments in the various options, next to balance and disparity. In addition, the emergence of option three is now modeled as an instantaneous event. However, in many cases innovations keep being modified and improved once they have emerged (witness the notions of product and industry life cycle). This might be incorporated by using a sequence of altering values of option three. Next, one could investigate the nature of the marginal benefits to 
diversity. The presence of a greater number of options may give rise to more spillovers, and their number would at first seem to be proportional to the number of combinations among options possible. However, one cannot exclude decreasing returns to the number of options. This problem becomes more complex if modular innovation can involve more than two components (i.e. recombination with three or more inputs). Analysis of recombinant innovation as here also offers an easy connection with the notion of coevolution (of different technologies or even of technology and science). An entirely different type of extension is to add selection, for example with replicator dynamics. This could focus on competing instead of complementary techniques. Finally, a number of empirical issues are relevant as well. Perhaps the crucial question is how a system of options can be demarcated to capture the relevant spillover or recombination opportunities. Demarcation is difficult if one believes that in principle not any combination in the economy can be excluded, which would ultimately suggest a global perspective. Historical case studies of clear recombinant innovations, including interviews with core players about the 'search space', might shed some light on this issue.

\section{References}

Andersen, E.S., 1994. Evolutionary Economics: Post-Schumpeterian Contributions. London: Pinter.

Arrow, K.J., Fisher, A.C., 1974. Environmental preservation, uncertainty, and irreversibility. Quarterly Journal of Economics 88, 312-319.

Arthur, W.B., 1989. Competing technologies, increasing returns, and lock-in by historical events. Economic Journal 99, 116-131.

Aslaksen, I., Synnestvedt, T., 2004. Are the Dixit-Pindyck and the Arrow-Fisher-HenryHanemann option values equivalent? Discussion Papers No. 390, Statistics Norway, Oslo.

Baumgärtner, S., 2004. Optimal investment in multi-species protection: Interacting species and ecosystem health. EcoHealth 1, 101-110.

Besen, S.M., Farrell, J. 1994. Choosing how to compete: Strategies and tactics in standardization. Journal of Economic Perspectives 8(2), 117-131.

Birchenhall, C., 1995. Modular technical change and genetic algorithms. Computational Economics 8, 233-253.

Birge, J.R., Rosa, C.H., 1996. Incorporating investment uncertainty into greenhouse policy models. The Energy Journal 17, 79-90.

Black, F., Scholes, M., 1973. The pricing of options and corporate liabilities. Journal of Political Economy 81, 637-654.

Cantner, U., Pyka, A., 2001. Classifying technology policy from an evolutionary perspective. Research Policy 30, 759-775.

Carroll, G.R., Hannan, M.T., 2000. The Demography of Corporations and Industries. Princeton, NJ: Princeton University Press,.

Common, M., Perrings, C., 1992. Towards an ecological economics of sustainability. Ecological Economics 6, 7-34.

David, P.A., 1986. Narrow windows, blind giants and angry orphans: the dynamics of systems rivalries and dilemmas of technology policy. CEPR Paper 10, Stanford Institute for Economic Policy Research, Stanford University, March 1986. 
David, P.A.,, 1987. Some new standards for the economics of standardization in the information age. In: Dasgupta, P., Stoneman. P. (Eds.). Economic Policy and Technological Performance. Cambridge: Cambridge University Press, 206-239.

David, P.A., Greenstein, S., 1990. The economics of compatibility standards: An introduction to recent research. Economics of Innovation and New Technology 1, 3-41.

Dixit, A.K., Pindyck, R.S., 1994. Investment under Uncertainty. Princeton, N.J.: Princeton University Press.

Dopfer, K. (Ed.), 2005. Economics, Evolution and the State: Governance of Complexity. Cheltenham, U.K.: Edward Elgar.

Dosi, G., Freeman, C., Nelson, R., Silverberg, G., Soete. L. (Eds.), 1988. Technical Change and Economic Theory. London: Pinter Publishers.

Eiben, A.E., Smith, J.E., 2003. Introduction to Evolutionary Computing. Berlin: Springer.

Epstein, L.G., 1980. Decision making and the temporal resolution of uncertainty. International Economic Review 21, 269-283.

Esteban, J.M., Ray, D., 1994. On the measurement of polarization. Econometrica. 62, 819851.

Fisher, A.C., 2000. Investment under uncertainty and option value in environmental economics. Resource and Energy Economics 22, 197-204.

Fisher, AC, Krutilla, J.V., Cicchetti, C.J., 1972. The economics of environmental preservation. American Economic Review 62, 605-619.

Fisher, R.A., 1930. The Genetical Theory of Natural Selection. Oxford: Clarendon.

Foray D., 1997. The dynamic implications of increasing returns: Technological change and path dependent inefficiency. International Journal of Industrial Organization, 15, 733752.

Freeman, C., 1987. Technology Policy and Economic Performance. London: Pinter.

Frenken, K., 2000. A complexity approach to innovation networks. Research Policy 29, 257 272.

Frenken, K., 2007. A complex systems methodology to transition management. Lecture at Workshop on "Computational and Mathematical Approaches to Societal Transitions". 26 Februari - 2 March 2007, Lorentz Center, Leiden University.

Frenken, K., Nuvolari, A., 2004. The early development of the steam engine: An evolutionary interpretation using complexity theory. Industrial and Corporate Change 13, 419-450.

Frenken, K., Saviotti, P.P., Trommetter, M., 1999. Variety and niche creation in aircraft, helicopters, motorcycles and microcomputers. Research Policy 28, 469-488.

Garcia, R., Calantone, R., Levine, R., 2003. The role of knowledge in resource allocation to exploration versus exploitation in technologically oriented organizations. Decision Sciences 24, 323-349.

Geels, F.W., 2002. Technological transitions as evolutionary reconfiguration processes: A multi-level perspective and a case-study. Research Policy 31, 1257-1274.

Geels, F.W., 2007. Analysing the breakthrough of rock 'n' roll (1930-1970): Multi-regime interaction and reconfiguration in the multi-level perspective. Technological Forecasting and Social Change 74, 1411-1431.

Gollier, C., Jullien, B., Treich, N., 2000. Scientific progress and irreversibility: An economic interpretation of the precautionary principle. Journal of Public Economics 75, 229-253.

Gunderson, L.H., Holling, C.S. (Eds.), 2002. Panarchy: Understanding Transformations in Human and Natural Systems. Washington D.C.: Island Press.

Hannan, M.T., Freeman, J., 1977. The population ecology of organizations. American Journal of Sociology 83, 929-84.

Hannan, M.T., Freeman, J., 1989. Organizational Ecology. Cambridge, MA: Harvard University Press.

Henderson, R., Clark, K., 1990. Architectural innovation. Administrative Science Quarterly 35, 9-30.

Henry, C., 1974. Investment decisions under uncertainty: The irreversibility effect. American Economic Review 64, 1006-12. 
Holling, C.S., 1973. Resilience and stability of ecological systems. Annual Review of Ecological Systems 4, 1-24.

Holling, C.S., 1986. The resilience of terrestrial ecosystems: Local surprise and global change. In: Clark, W.C., Munn, R.E. (Eds.). Sustainable Development of the Biosphere. Cambridge: Cambridge University Press.

Hong, L., Page, S.E., 2004. Groups of diverse problem solvers can outperform groups of high-ability problem solvers. Proceedings of the National Academy of Sciences of the USA 101, 16385-89.

Iwai, K., 1984. Schumpeterian dynamics, part I: An evolutionary model of innovation and imitation. Journal of Economic Behaviour and Organization 5, 159-190.

Kauffman, S.A., 1993. The Origins of Order: Self-Organization and Selection in Evolution. Oxford: Oxford University Press.

Kolstad, C.D., 1994. The timing of $\mathrm{CO}_{2}$ control in the face of uncertainty and learning. In: van Ierland, E.C. (Ed.). International Environmental Economics. Amsterdam: Elsevier Science Publishers, 75-96.

Krutilla, J.V., 1967. Conservation reconsidered. American Economic Review 57, 777-784.

Krysiak, F., Krysiak, D., 2006. Sustainability with uncertain future preferences. Environmental and Resource Economics 33, 511-531.

Levin, S., Barrett, S. Aniyar, S., Baumol, W., Bliss, C., Bolin, B., Dasgupta, P., Ehrlich, P., Folke, C., Gren, I., Holling, C.S., Jansson, A., Jansson, B.-O., Mäler, K.-G., Martin, D., Perrings C., Sheshinski, E., 1998. Resilience in natural and socioeconomic systems. Environment and Development Economics 3, 222-235.

Levinthal, D., March, J.G., 1981. A model of adaptive organizational search. Journal of Economic Behaviour and Organization 2, 307-333.

Lewin, A.,Y., Long, C.P., Carrol, T.N., 1999. The coevolution of new organizational forms. Organization Science 10, 535-551.

Luehrman, T., 1998. Strategy as a portfolio of real options. Harvard Business Review 76, 8999.

Lundvall, B.-Å., 2007. National innovation systems: from List to Freeman. In: Hanusch, H., Pyka, A. (Eds.). Elgar Companion to Neo-Schumpeterian Economics. Cheltenham: Edward Elgar, 872-881.

Maignan, C., Ottaviano, G., Pineli, D., Rullani, F., 2003. Bio-ecological diversity vs. socioeconomic diversity: A comparison of existing measures. FEEM Working Paper no. 13.2003. Fondazione Eni Enrico Mattei, Milano.

March, J.G., 1991. Exploration and exploitation in organizational learning. Organization Science 2, 71-87.

Markowitz, H.M., 1952. Portfolio selection. Journal of Finance 7, 77-91.

Maynard Smith, J., Szathmáry, E., 1995. The Major Transitions in Evolution. Oxford: Oxford University Press.

Metcalfe, J.S., 1994. Competition, Fisher's principle and increasing returns to selection. Journal of Evolutionary Economics 4, 327-346.

Metcalfe, J.S., 1995. The economic foundations of technology policies: Equilibrium and evolutionary perspectives. In: Stoneman, P. (Ed.). Handbook of the Economics of Innovation and Technological Change. Oxford: Blackwell, 409-511.

Metcalfe, J.S., 1998. Evolutionary Economics and Creative Destruction. London: Routledge.

Mokyr, J., 1990. The Lever of the Riches: Technological Creativity and Economic Progress. Oxford: Oxford University Press.

Munro, A., 1997. Economics and biological evolution. Environmental and Resource Economics 9, 429-449.

Murray, F., 2002. Innovation as co-evolution of scientific and technological networks: Exploring tissue engineering. Research Policy 31, 1389-1403.

Nelson, R., 1993. National Innovation Systems. New York: Oxford University Press.

Nelson, R., Winter, S., 1982. An Evolutionary Theory of Economic Change. Cambridge, MA: Harvard University Press. 
Olson, O., Frey, B.S., 2002. Entrepreneurship as recombinant growth. Small Business Economics 19, 69-80.

Pelikan, P., Wegner, G. (Eds.), (2003). The Evolutionary Analysis of Economic Policy. Cheltenham, U.K.: Edward Elgar.

Pimm, S.L., 1984. The complexity and stability of ecosystems. Nature 307, 321-326.

Pindyck, R.S, 1991. Irreversibility, uncertainty, and investment. Journal of Economic Literature, 29(3), 1110-48,

Pindyck, R.S., 2000. Irreversibilities and the timing of environmental policy. Resource and Energy Economics 22, 233-259.

Porter R., 1982. The new approach to wilderness preservation through benefit-cost analysis. Journal of Environmental Economics and Management 9, 59-80.

Potts, J., 2000. The New Evolutionary Microeconomics: Complexity, Competence, and Adaptive Behavior. Cheltenham, U.K.: Edward Elgar.

Rammel, C., van den Bergh, J.C.J.M., 2003. Evolutionary policies for sustainable development: Adaptive flexibility and risk minimising. Ecological Economics 47, 121133.

Sartorius, C., Zundel, S. (Eds.), 2005. Time Strategies, Innovation and Environmental Policy. Cheltenham, U.K.: Edward Elgar.

Saviotti, P.P., Mani, G.S., 1995. Competition, variety and technological evolution: A replicator dynamics model. Journal of EvoIutionary Economics 5, 369-392.

Schlosser, G., Wagner, G.P., 2004. Modularity in Development and Evolution. Chicago: University of Chicago Press.

Schot, J., Geels, F.W., 2007. Niches in evolutionary theories of technical change: A critical survey of the literature. Journal of Evolutionary Economics 17, 605-622.

Schumpeter, J.A., 1934. The Theory of Economic Development. Cambridge: Harvard University Press,.

Shackle, G.L.S., 1949. Expectation in Economics. Cambridge: Cambridge University Press,.

Sharpe, W.F., 1964. Capital asset prices: A theory of market equilibrium under conditions of risk. Journal of Finance 19, 425-442.

Smith, V.K., Krutilla, J.V., 1979. Endangered species, irreversibilities, and uncertainty: A comment. American Journal of Agricultural Economics 61, 371-75.

Stirling, A., 1998. On the economics and analysis of diversity. SPRU Working Paper Number 28, University of Sussex.

Stirling, A., 2004. Diverse designs: Fostering technological diversity in innovation for sustainability. Science and Technology Policy Research (SPRU), University of Sussex, Brighton.

Stirling, A., 2007. A general framework for analysing diversity in science, technology and society. Journal of the Royal Society Interface 4, 707-719.

Swanson, T.M., 1994. The economics of extinction revisited and revised: A generalised framework for the analysis of the problems of endangered species and biodiversity losses. Oxford Economic Papers 46(Supplement), 800-821.

Tisdell, C., Seidl, I., 2004. Niches and economic competition: Implications for economic efficiency, growth and diversity. Structural Change and Economic Dynamics 15, 119 135.

Tsur, Y., Zemel, A., 2006. Endogenous recombinant growth. Discussion Paper No. 2.06. The Department of Agricultural Economics and Management. The Hebrew University of Jerusalem.

Ulph, A., Ulph, D., 1997. Global warming, irreversibility and learning. Economic Journal 107, 636-650.

van den Bergh, J.C.J.M., 2007. Evolutionary thinking in environmental economics. Journal of Evolutionary Economics 17, 521-549.

van den Bergh, J.C.J.M., Faber, A., Idenburg, A.M., Oosterhuis, F.H., 2006. Survival of the greenest: Evolutionary economics and policies for energy innovation. Environmental Sciences 3, 57-71.

van der Heide, C.M., van den Bergh, J.C.J.M., van Ierland, E.C., 2005. Extending Weitzman's 
economic ranking of biodiversity protection: combining ecological and genetic considerations. Ecological Economics 55, 218-223.

Walters, C., 1986. Adaptive Management of Renewable Resources. New York: MacMillan.

Watson, R.A., 2006. Compositional Evolution: The Impact of Sex, Symbiosis, and Modularity on the Gradualist Framework of Evolution. Cambridge, MA: MIT Press.

Weisbrod, B.A., 1964. Collective consumption services of individual consumption goods. Quarterly Journal of Economics 78, 471-477.

Weitzman, M.L., 1992. On diversity. Quarterly Journal of Economics 107, 363-405.

Weitzman, M.L., 1998a. The Noah's ark problem. Econometrica 66, 1279-1298.

Weitzman, M.L., 1998b. Recombinant growth. Quarterly Journal of Economics 113, 331-360.

Witt, U., 2003. Economic policy making in evolutionary perspective. Journal of Evolutionary Economics 13, 77 - 94.

Woodward, R.T., Bishop, R.C., 2000. Efficiency, sustainability and global warming. Ecological Economics 14, 101-111.

Young, R.A., 2001. Uncertainty and the Environment: Implications for Decision Making and Environmental Policy. Cheltenham, U.K.: Edward Elgar. 


\section{Figures (\#=7)}

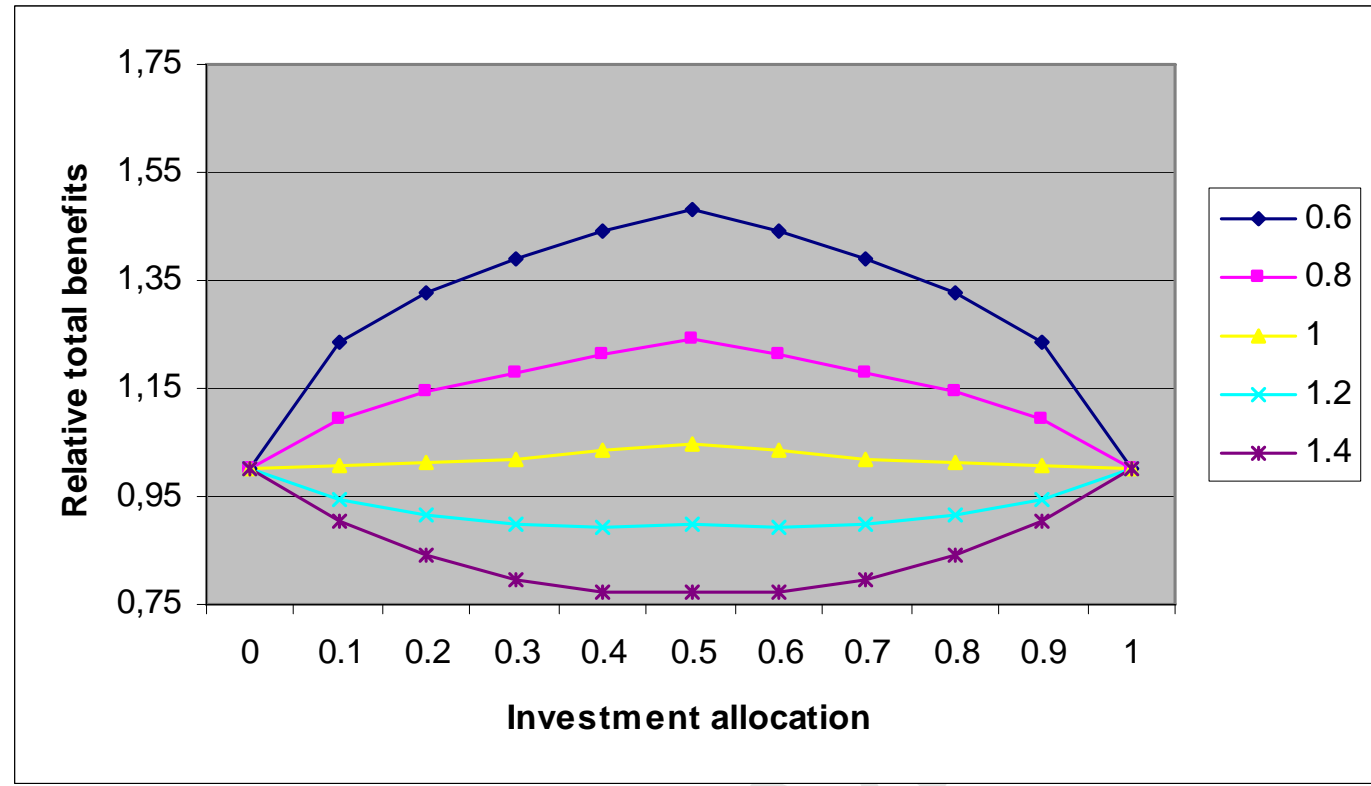

Figure 1. Relative total benefits of diversity in investment allocation for different returns to scale (0.6-1.4)

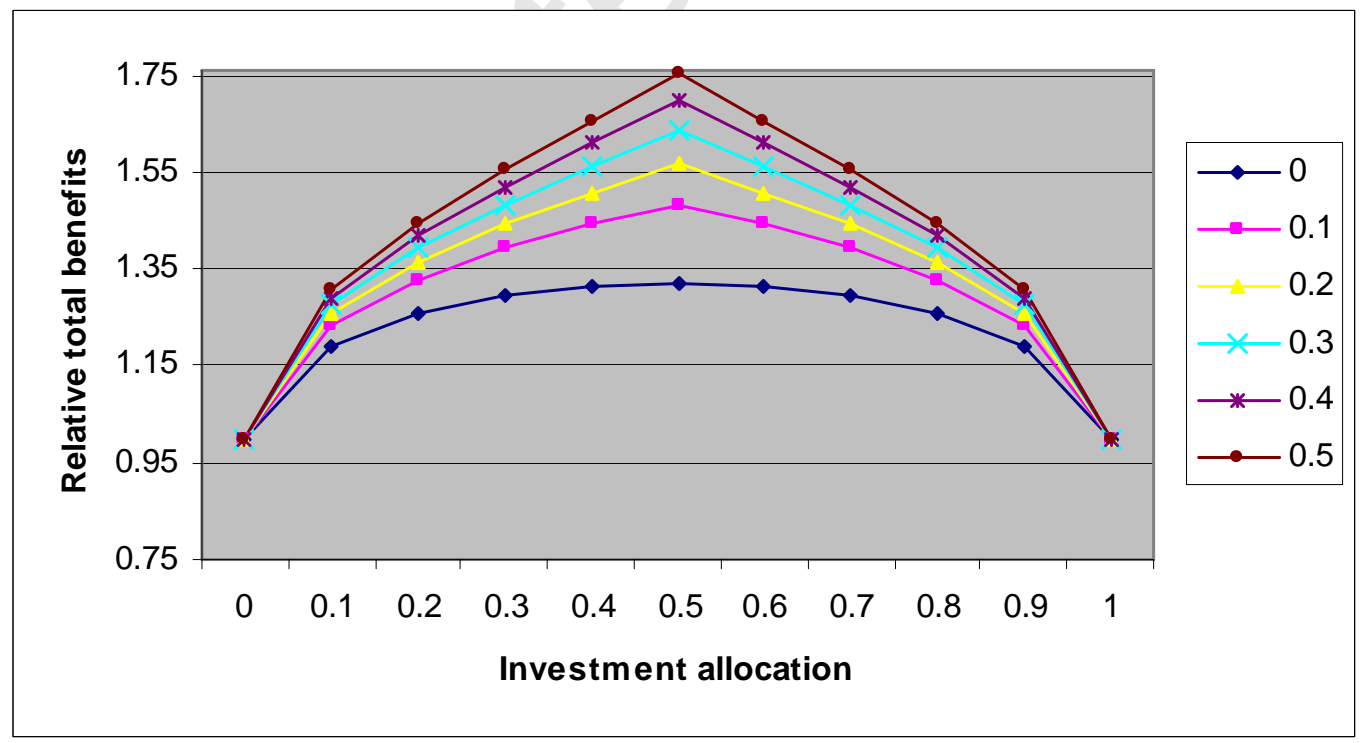

Figure 2. Relative total benefits of diversity in investment allocation for different probability factors (0-0.5), given decreasing returns to scale $(s=0.6)$ 


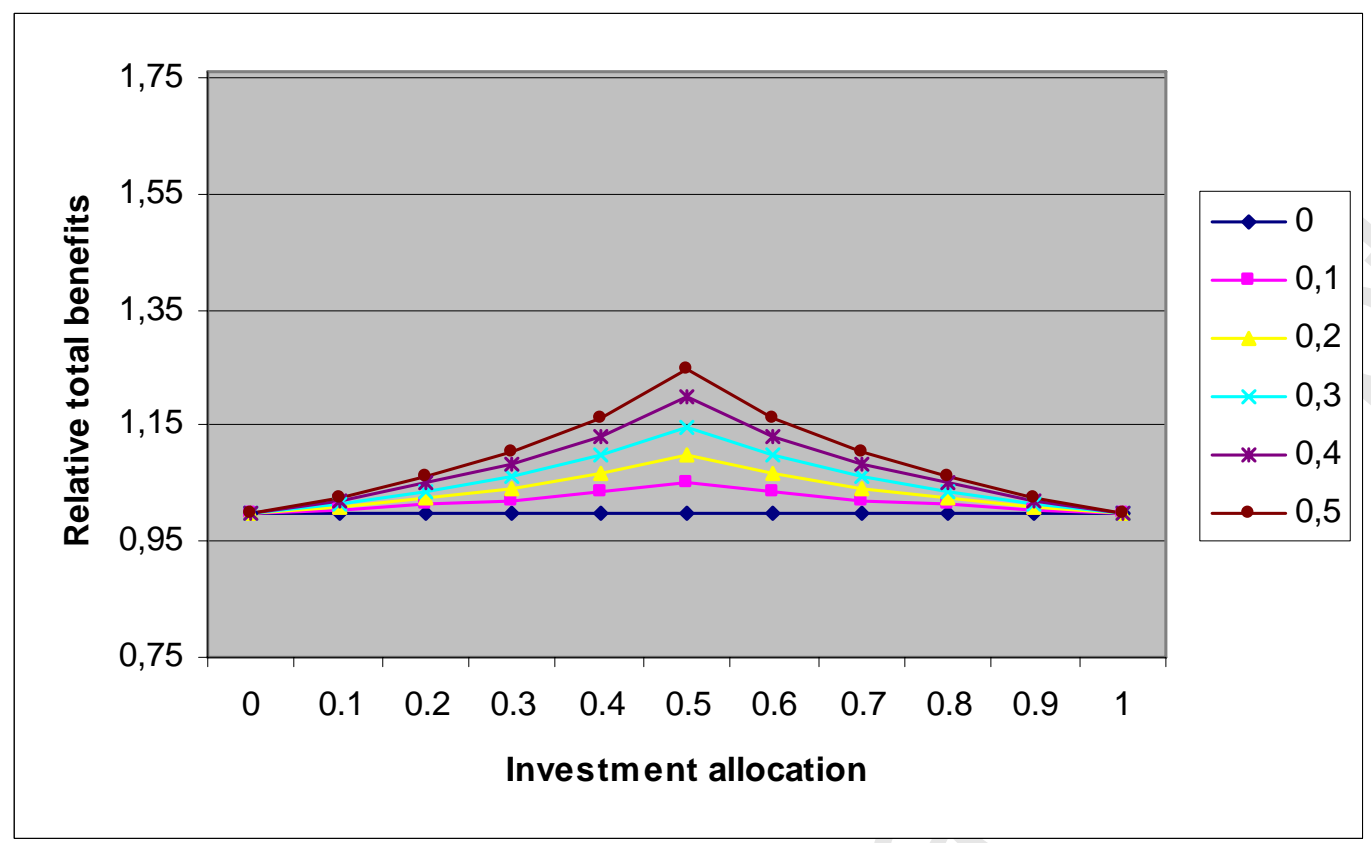

Figure 3. Relative total benefits of diversity in investment allocation for different probability factors (0-0.5), given constant returns to scale $(s=1)$

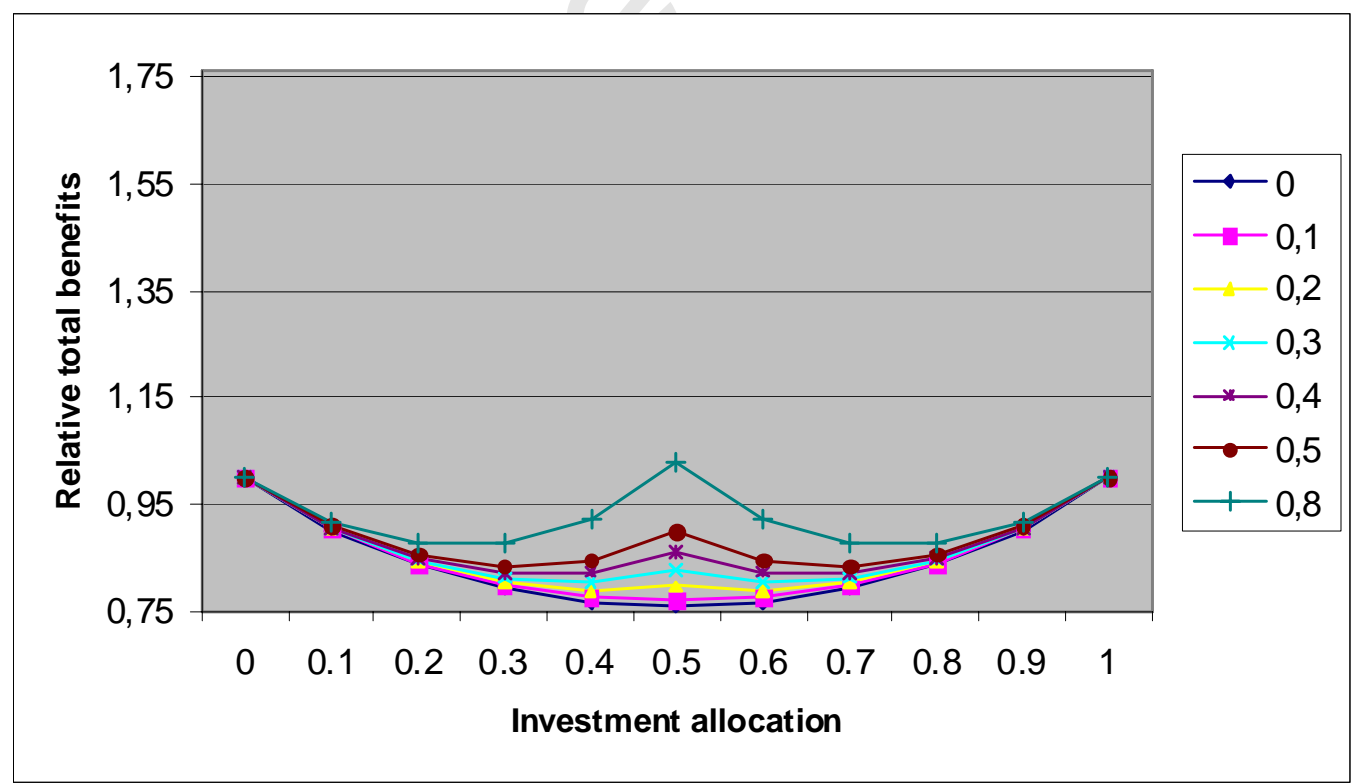

Figure 4. Relative total benefits of diversity in investment allocation for different probability factors (0-0.8), given increasing returns to scale $(s=1.4)$ 




Figure 5. Relative total benefits of diversity in investment allocation for different disparity levels (1-2), given constant returns to scale $(s=1)$

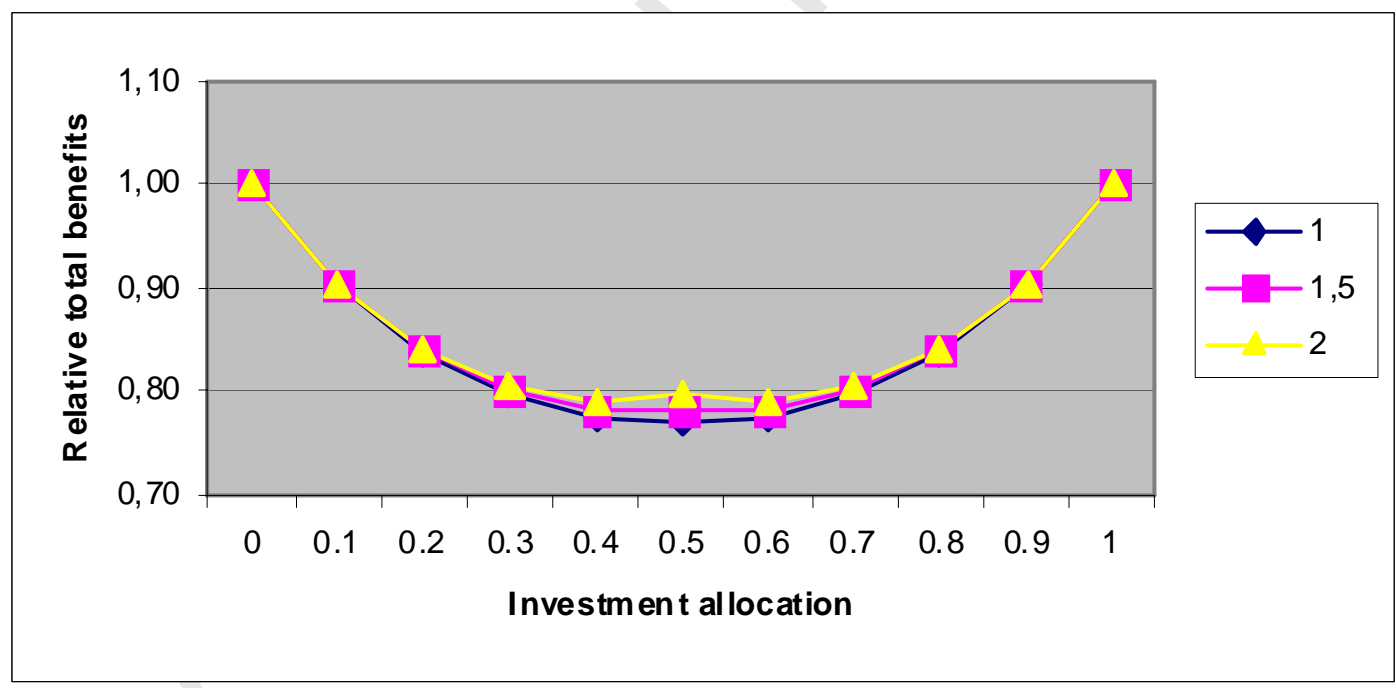

Figure 6. Relative total benefits of diversity in investment allocation for different disparity levels $(1-2)$, given increasing returns to scale $(s=1.4)$ 


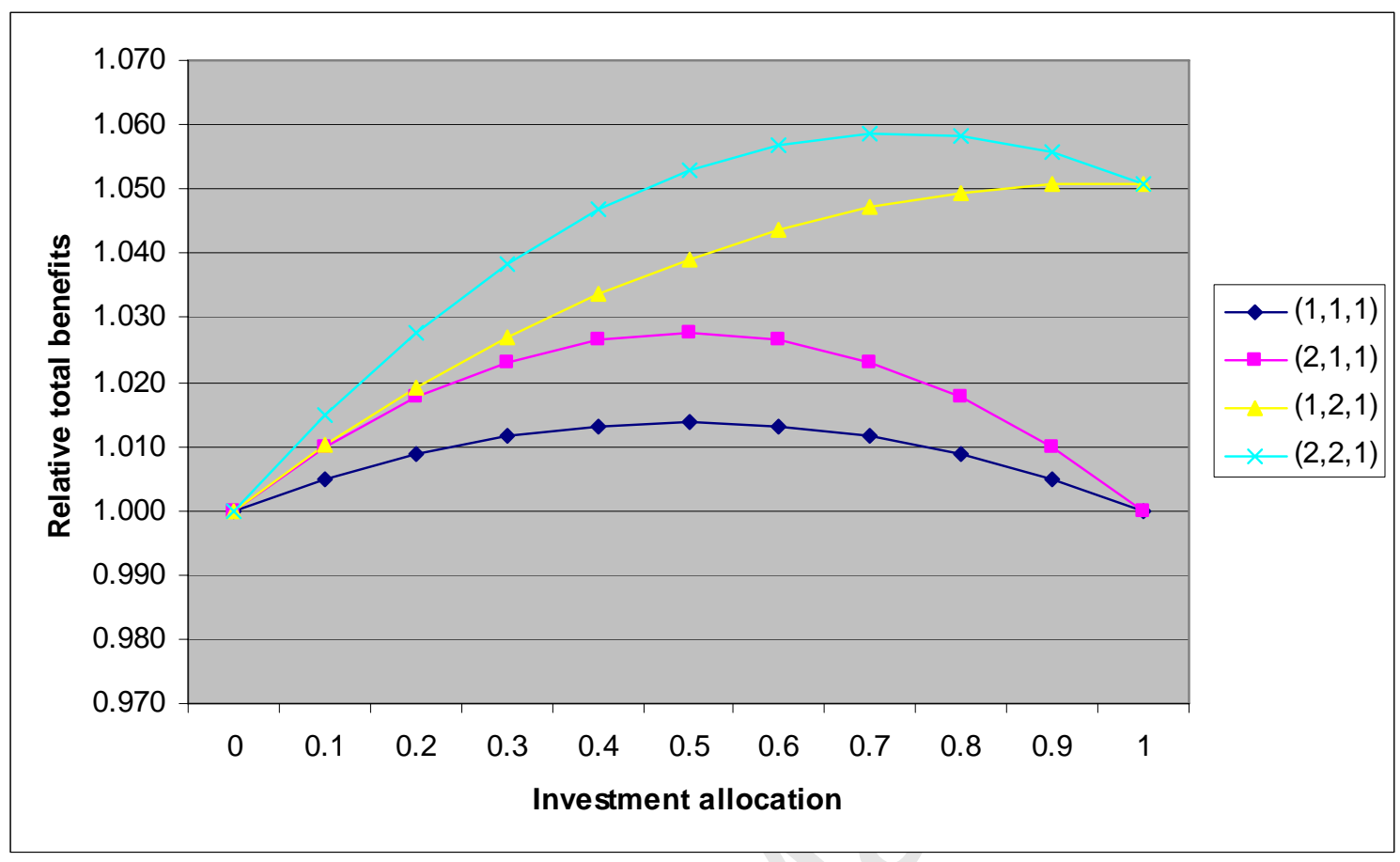

Figure 7. Relative total benefits of diversity in investment allocation for different disparity combinations ( $\left.d_{12} d_{13} d_{23}\right)$, given constant returns to scale 